\title{
LA CRISIS Y EL DERECHO A LA SALUD: UN DIAGNÓSTICO DE TENSIONES Y SOLUCIONES
}

\author{
Fernando CEnTEnera SÁnCHez-SeCo \\ Área de Filosofía del Derecho \\ Departamento de Ciencias Jurídicas \\ Facultad de Derecho \\ Universidad de Alcalá de Henares \\ fernando.centenera@uah.es
}

\begin{abstract}
RESUMEN
Desde hace varios años España está atravesando una crisis. En este contexto, el argumento de la insuficiencia económica ba motivado numerosos recortes en diferentes ámbitos, entre ellos el de la sanidad. La primera parte de este trabajo se refiere a esta circunstancia y a las consecuencias negativas que de la misma se ban derivado. A continuación, con vistas a ofrecer un análisis jurídico de la situación, se considera la regulación del derecho a la salud en la Constitución y en el ámbito internacional. El trabajo también incluye una propuesta de racionalidad normativa que contempla la cuestión de la eficiencia y otras que tienen un lugar ineludible en el análisis del contexto que se estudia.
\end{abstract}

Palabras clave: crisis, salud, eficiencia, racionalidad normativa.

\section{ABSTRACT}

Spain has been living a crisis for a few years now. In such context, with the point that the economy is poor a number of shortcuts in different areas have taken place, among which those in the NHS. The first part of this piece of work focuses on this issue and the negative consequences derived from such an issue. Following, aiming at an analysis of the issue from a legal point of view we consider the ruling of the right to bealth in the Constitution and on an international basis. This work also includes a proposal of normative rationality observing the issue of efficiency, as well as others with a key role in the analysis of the context of study.

Keywords: Crisis, health, efficiency, normative rationality.

\section{ZUSAMMENFASSUNG}

Seit einigen Jabren unterliegt Spanien einer Wirtschaftskrise. In diesem Zusammenhang wurden binsichtlich der feblenden finanziellen Mittel zablreiche Mittelkürzungen in verschiedenen Bereichen vorgenommen, unter anderem auf dem Gebiet des Gesundheitswesens. Der erste Teil dieser Arbeit bezieht sich auf diesen Umstand und seine negativen Auswirkungen, die daraus entstanden sind. Anschlie- 
Bend wird eine rechtliche Untersuchung der Situation vorgenommen; es wird die gesetzliche Regelung des Rechts auf Gesundheit in der Verfassung und im internationalen Zusammenhang untersucht. Die Arbeit umfasst auch einen Vorschlag zur vernünftigen Normgebung und betrachtet die Frage der Effizienz sowie andere Fragen, die unausweichlich ibren Platz im Zusammenhang der Untersuchung haben.

Schlüsselwörter: Wirtschaftskrise, Gesundheit, Effizienz, vernünftige Normgebung.

SUMARIO: I. INTRODUCCIÓN.-II. LAS MEDIDAS ADOPTADAS.-III. LAS CONSECUENCIAS.-IV. EL PUNTO DE VISTA JURÍDICO.-1. La perspectiva constitucional.-2. La perspectiva internacional.-3. Sobre la justificación de las medidas adoptadas.-V. POR UN PROCESO DE RACIONALIDAD EX ANTE.-1. Sobre la eficiencia.-2. Más allá de la eficiencia.-3. Soluciones para las tensiones.-VI. A MODO DE EPÍLOGO: LOS PROBLEMAS CONTINÚAN.

\section{INTRODUCCIÓN}

Desde el año 2007 España atraviesa una crisis que ha motivado recortes en diferentes ámbitos, entre ellos el de la sanidad. Ya en el año 2010, la deuda en este contexto se cifraba entre 7.500 y 15.000 millones de euros ${ }^{1}$. Sin embargo, el problema del déficit no es genuino del periodo de crisis. Anteriormente también estaba presente ${ }^{2}$, si bien es cierto que con la llegada de la crisis se acentuó el argumento de que la deuda era incompatible con la sostenibilidad del Sistema Nacional de Salud ${ }^{3}$. Conviene, no obstante, señalar que, según algunos estudios, el gasto público sanitario se ajustaba a la media que establecía la Organización para la Cooperación y Desarrollo Económicos ${ }^{4}$.

${ }^{1}$ B. González López-Valcárcel, «La sanidad en tiempos de crisis», Revista Economistas, núm. 126 extra (2011), pp. 127-133, esp. p. 127, disponible en bttp://www.econ.upf. edu/ jimenez/my-public-files/La-sanidad-en-tiempos-de-crisis.pdf (fecha de consulta: 11 de diciembre de 2015).

${ }^{2}$ Ibid., p. 129, y F. I. SÁnChez, J. M. ABELlán y J. Oliva, «Gestión pública y gestión privada de servicios sanitarios públicos: más allá del ruido y la furia, una comparación internacional», Documento de Trabajo, núm. 4 (2013), pp. 1-13, esp. p. 3, disponible en bttp://www. realinstitutoelcano.org/wps/wcm/connect/7e174d004ece1139931b9f2a39eb3cc0/DT4-2013Sanchez-Abellan-Oliva-Servicos-Sanitarios-Publicos.pdf?MOD=AJPERESECACHEID=7e174d 004ece1139931b9f2a39eb3cc0 (fecha de consulta: 11 de diciembre de 2015).

3 J. Cantero Martínez, «Constitución y derecho a la protección de la salud. ¿Existe algún límite frente a los recortes sanitarios?», Revista CESCO de Derecho de Consumo, núm. 8 (2012), pp. 1-26, esp. p. 2, disponible en https://ruidera.uclm.es/xmlui/bitstream/ bandle/10578/3522/Constitucion \%20y\%20derecho\%20a\%20la\%20proteccion \%20de\%20 la\%20salud.pdf?sequence $=1$ (fecha de consulta: 11 de diciembre de 2015).

${ }^{4}$ V. NAVARRO, «El error de las políticas de austeridad, recortes incluidos, en la sanidad pública», Gaceta Sanitaria, núm. 26/2 (2012), pp. 174-175, esp. p. 174, disponible en 
El argumento de la insuficiencia económica ha venido justificando numerosas medidas que han afectado a diversas parcelas del ámbito sanitario y que han traído consigo varias consecuencias negativas. En la primera parte de este trabajo nos referiremos a estas circunstancias. A continuación, con la intención de ofrecer un punto de vista jurídico a propósito de los aspectos constatados, nos detendremos en la regulación del derecho a la salud en la Constitución y en determinados aspectos del contexto internacional. De este recorrido resulta una conclusión, que nos parece especialmente relevante para nuestro trabajo, que pretende analizar el tema en cuestión desde el punto de vista de la racionalidad de las políticas públicas: la necesidad de aportar buenas razones para llevar a cabo las medidas desarrolladas; un requerimiento que, además, se encuentra sometido a control jurisprudencial. Sin duda, este es necesario e importante, y por eso reservamos un lugar a aquel en estas páginas. Sin embargo, en este estudio pretendemos reivindicar especialmente — aunque no de forma exclusiva, como después se apuntará- el control ex ante en el proceso de elaboración de normas o de políticas públicas, dado que, a nuestro juicio, una correcta gestión en este ámbito podría haber supuesto un antídoto para evitar, o al menos aminorar, las consecuencias no deseadas a las que nos referíamos anteriormente ${ }^{5}$. A fin de cuentas, lo que se pretende analizar es

bttp://scielo.isciii.es/scielo.php?script=sci_arttextEpid=S0213-91112012000200014 (fecha de consulta: 11 de diciembre de 2015); F. Angora Mazuecos, «Público/privado versus derecho/negocio en materia de salud», Revista Clínica de Medicina de Familia, núm. 4/3 (2011), pp. 219-222, esp. pp. 219 y 220, disponible en http://scielo.isciii.es/scielo.php?pid=S1699695X2011000300006Escript=sci_arttext (fecha de consulta: 11 de diciembre de 2015); E. GonZÁlez Hidalgo, «Un nuevo sistema sanitario: el falso debate entre la sostenibilidad y el negocio», Revista Clínica de Medicina de Familia, núm. 5/2 (2012), pp. 79-80, esp. p. 79, disponible en http://www.redalyc.org/articulo.oa? $\mathrm{id}=169624439001$ (fecha de consulta: 11 de diciembre de 2015), y P. Pérez Solís y Á. Díaz Álvarez, «El Real Decreto 16/2012 y el cambio de modelo sanitario», Enfermería Comunitaria, núm. 1/2 (2013), pp. 38-47, esp. p. 41, disponible en http://www.seapaonline.org/UserFiles/File/Revistas/Primavera2013/ El\%20Real\%20Decreto\%2016_2012\%20y\%20el\%20Cambio\%20de\%20Modelo\%20Sanitario.pdf (fecha de consulta: 11 de diciembre de 2015).

5 En los años recientes hemos llevado a cabo trabajos en esta línea, considerando algunos de los aspectos de ciencia de la legislación que aquí también se tratarán a propósito de problemas diferentes. Así, F. Centenera SÁnchez-SeCo, «¿Podríamos haber tenido una ley de violencia de género de mayor calidad?», Derechos y Libertades, núm. 25 (2011), pp. 237-268, disponible en http://e-archivo.uc3m.es/bitstream/bandle/10016/17110/DyL2011-25-centenera.pdf? sequence $=5$ (fecha de consulta: 20 de junio de 2016), e ÍD., «Algunas reflexiones acerca del Real Decreto-ley 3/2012: sobre el desempleo y más allá», Cuadernos Electrónicos de Filosofía del Derecho, núm. 32 (2015), pp. 54-71, disponible en bttps://ojs. uv.es/index.php/CEFD/article/view/5213/7414 (fecha de consulta: 20 de junio de 2016). También hemos presentado la siguiente comunicación (que se publicará en los próximos meses) en el III Congreso Internacional del PRADPI-FIO-PROFIO: Ombudsman y colectivos 
la tensión entre eficiencia y justicia. Como es sabido, se trata de un planteamiento contemplado en numerosos estudios dedicados a las políticas públicas que, además, encuentra reflejo en algunos trabajos desarrollados a propósito del tema que nos ocupa. En este estudio hemos tenido todo ello en cuenta, aunque prestamos especial atención a los siguientes aspectos, desarrollados en base a un esquema que es deudor de las recomendaciones procedentes de la ciencia de la legislación. En primer lugar, el carácter no necesario, al menos en numerosos casos, de la relación establecida entre las medidas adoptadas y la eficiencia. En segundo lugar, la reivindicación de políticas públicas más comprometidas con la justicia. En tercer lugar, la constatación de una panoplia de alternativas más generosa que las desarrolladas, capaces de aliviar la tensión diagnosticada. Para concluir, recordamos que en los meses más recientes algunos problemas siguen presentes y que, por tanto, aun cuando los planteamientos sobre lo que podría haber sido un proceso ex ante más deseable no se puedan retrotraer en el tiempo, quizá en alguna medida puedan ser de utilidad para reconsiderar la situación actual.

\section{LAS MEDIDAS ADOPTADAS}

Aunque, como se ha dicho, el inicio de la crisis se suele fijar en el año 2007, las restricciones comenzaron a partir del año $2010^{6}$. La sanidad se financia con impuestos recaudados por el Estado, pero el gasto se lleva a cabo por parte de las Comunidades Autónomas ${ }^{7}$. En este último contex-

en situación de vulnerabilidad: F. CENTENERA SÁnCHEZ-SECO, «Las acciones de las Defensorías del Pueblo sobre el acceso de inmigrantes en situación irregular a la asistencia sanitaria: a propósito de los análisis sobre racionalidad normativa». En este estudio puede verse un desarrollo más pormenorizado que el recogido en el presente trabajo, en relación al colectivo citado en el título, planteado desde la perspectiva de las Defensorías del Pueblo.

${ }^{6}$ B. GonZález López-VAlCÁrCEL, «La sanidad...», op. cit., p. 129.

7 R. RIEZNIK, «La mercantilización de la salud pública en España», Hic Rhodus. Crisis capitalista, polémica y controversias, núm. 4 (2013), pp. 51-56, disponible en bttp://biblioteca.clacso.edu.ar/Argentina/iigg-uba/20140625054507/340-1268-1-PB.pdf (fecha de consulta: 11 de diciembre de 2015). Sobre las competencias en materia de sanidad, en el caso del Estado y en el de las Comunidades Autónomas, véanse los arts. 149.1.16 y 148.1.21 de la Constitución, respectivamente. El proceso de transmisión de competencias al sector autonómico culminó en el año 2002. Sobre la cuestión vid. P. Acosta GALLO, «La nueva regulación de la tarjeta sanitaria individual y los problemas financieros de la sanidad pública», Revista CESCO de Derecho de Consumo, núm. 8 (2013), pp. 27-41, esp. p. 31, disponible en http://cesco.revista.uclm.es/index.php/cesco/article/view/404/346 (fecha de consulta: 11 de diciembre de 2015), y L. GONZÁLEZ MorÁn, «Introducción al derecho a la asistencia 
to, la sanidad representa entre el 35 y el 40 por 100 del presupuesto real ${ }^{8}$. En la situación de crisis descrita, las Comunidades Autónomas, endeudadas y tras perder la confianza para el préstamo, han buscado por todos los medios reducir los gastos en diferentes ámbitos, entre ellos el sanitario?. Quizá sea representativo el dato de que en el año 2013 el presupuesto sanitario de las Comunidades Autónomas se redujo en unos 7.500 millones de euros con respecto a $2010^{10}$.

Más concretamente, en relación a las medidas adoptadas podemos decir que se han llevado a cabo mediante reducciones de costes en el ámbito de recursos materiales, con resultados concretados, por ejemplo, en cierres de plantas, quirófanos, puntos de atención continuada o de urgencias, centros en determinadas franjas horarias, o bien en la eliminación de determinados servicios, como algunas unidades de cuidados paliativos. No menos relevantes son las restricciones en cuanto a recursos humanos. Desde esta perspectiva encontramos bajadas en los salarios, despidos de personal, restricciones de contratos eventuales en atención primaria, jubilaciones forzosas en las que se ha tenido en cuenta de forma exclusiva la edad, vacantes sin cubrir, etcétera ${ }^{11}$.

No podemos olvidar tampoco la alternativa de la privatización que, no obstante, está permitida por la legislación de años anteriores ${ }^{12}$. Una retros-

sanitaria», en J. GAFO (ed.), El derecho a la asistencia sanitaria y la distribución de recursos, Madrid, Universidad Pontificia Comillas, 1999, pp. 187-250, esp. p. 200.

${ }^{8}$ S. PeIRó, «Para salir del hoyo, lo primero es dejar de cavar», Atención Primaria, núm. 12 (2012), pp. 1-4, esp. p. 1, disponible en bttp://dx.doi.org/10.1016/j.aprim.2012.08.001 (fecha de consulta: 11 de diciembre de 2015), y B. GonZález LóPEZ-VAlCÁrCEL, «La sanidad...», op. cit., p. 128.

9 S. PEIRÓ, «Para salir...», op. cit., p. 1.

10 M. SÁNChez BAYLE, «La contrarreforma sanitaria», Papeles de relaciones ecosociales y cambio global, núm. 123 (2013), pp. 63-72, esp. p. 63, disponible en https://www.fubem. es/medialcdv/file/biblioteca/revista_papeles/123/La_contrarreforma_sanitaria_M_Sanchez_ Bayle.pdf (fecha de consulta: 11 de diciembre de 2015).

${ }_{11}$ Sobre las reducciones de gasto en los ámbitos señalados en el texto vid. M. SÁNCHEZ BAYLE, «La contrarreforma...», op. cit., p. 63; S. PEIRÓ, «Para salir...», op. cit., p. 1; J. CANTERO MarTíneZ, «Constitución y derecho...», op. cit., pp. 3 y 4; E. GÓNZÁlez Hidalgo, «Un nuevo sistema...», op. cit., p. 79; P. ACOSTA GALlO, «Restricciones de gasto, gestión privada y copago en el servicio público de salud», Revista CESCO de Derecho de Consumo, núm. 4 (2012), pp. 70-86, esp. p. 71, disponible en https://ruiderae.revista.uclm.es/index.php/cescol article/view/137/118 (fecha de consulta: 11 de diciembre de 2015), y B. GONZÁLEZ LÓPEZVALCÁRCEl y R. MENEU, «El gasto que está triste y azul. Debe preocupar más la salud que el gasto sanitario», Gaceta Sanitaria, núm. 26/2 (2012), pp. 176-177, esp. p. 177, disponible en bttp://scielo.isciii.es/pdf/gs/v26n2/debate2.pdf (fecha de consulta: 11 de diciembre de 2015).

${ }_{12}$ Debe tenerse en cuenta la Ley 15/1997, de 25 de abril, sobre habilitación de nuevas formas de gestión del Sistema Nacional de Salud. Sobre estas cuestiones vid. P. PÉrez Solís y Á. Díaz Álvarez, «El Real Decreto...», op. cit., p. 40. 
pectiva en el tiempo nos muestra la existencia de conciertos para servicios complementarios, lo que supone la remisión de pacientes a centros concertados o bien la externalización de servicios como la limpieza ${ }^{13}$. Más recientemente, no obstante, se ha observado la puesta en práctica del Modelo de Financiación Privada, con el que una empresa privada construye el centro de salud asumiendo además con ello la gestión de determinados servicios no asistenciales. En este caso los servicios asistenciales siguen siendo públicos ${ }^{14}$. Sin embargo, la apuesta por la privatización ha ido más allá, al menos en determinados contextos donde se ha apostado por el denominado Modelo Alzira, en el cual la empresa privada se encarga de la cobertura sanitaria integral, en atención primaria y especializada ${ }^{15}$.

En la lista de las medidas adoptadas que venimos bosquejando hemos de referirnos también al copago, que abarca los aspectos que aparecen en el Real Decreto-ley 16/2012, de 20 de abril, sobre medidas urgentes para garantizar la sostenibilidad del Sistema Nacional de Salud y mejorar la calidad y seguridad de sus prestaciones. En esta norma estatal se establece una cartera de servicios estructurada en tres categorías: servicios básicos, suplementarios y accesorios. El copago tiene lugar en los dos últimos tipos y, por tanto, se extiende a aspectos tales como las prestaciones farmacéuticas, las ortoprotésicas o los traslados no urgentes ${ }^{16}$. De este modo, quienes usan estos servicios han de pagar un porcentaje de su coste. Más adelante, una Resolución de septiembre de 2013 hizo extensible el copago a un importante número de medicamentos de farmacia hospitalaria ${ }^{17}$.

13 B. González López-Valcárcel, «La sanidad...», op. cit., p. 129; F. I. SÁnchez, J. M. Abellán y J. Oliva, «Gestión pública...», op. cit., p. 5, y R. RIEZnIK, «La mercantilización...», op. cit., p. 52.

${ }^{14}$ B. GonzÁlez López-Valcárcel, «La sanidad...», op. cit., p. 129; M. SÁnchez Bayle, «La contrarreforma...», op. cit., pp. 67 y 68; F. I. SÁncheZ, J. M. Abellán y J. Oliva, «Gestión pública...», op. cit., pp. 5 y 6 y R. RIEZNIK, «La mercantilización...», op. cit., p. 52.

15 B. González López-VAlCÁrCel, «La sanidad...», op. cit., pp. 129, 130; M. SÁNCHeZ BAYLE, «La contrarreforma...», op. cit., p. 68; R. RIEZNIK, «La mercantilización...», op. cit., p. 52, y P. Pérez Solís y Á. Díaz Álvarez, «El Real Decreto...», op. cit., pp. 40 y 41.

16 Real Decreto-ley 16/2012, de 20 de abril, de medidas urgentes para garantizar la sostenibilidad del Sistema Nacional de Salud y mejorar la calidad y seguridad de sus prestaciones, Boletín Oficial del Estado, núm. 98 (2012), pp. 31286-31288, disponible en bttp://www. boe.es/boe/dias/2012/04/24/pdfs/BOE-A-2012-5403.pdf (fecha de consulta: 11 de diciembre de 2015).

17 Resolución de 10 de septiembre de 2013, de la Dirección General de Cartera Básica de Servicios del Sistema Nacional de Salud y Farmacia, por la que se procede a modificar las condiciones de financiación de medicamentos incluidos en la prestación farmacéutica del Sistema Nacional de Salud mediante la asignación de aportación del usuario, Boletín Oficial del Estado, núm. 225 (2013), pp. 73113 y ss., disponible en bttps://www.boe.es/boe/ dias/2013/09/19/pdfs/BOE-A-2013-9709.pdf (fecha de consulta: 11 de diciembre de 2015). 
Para concluir, en la lista de medidas que venimos bosquejando resulta ineludible referirnos a otra recogida también en el Real Decreto-ley 16/2012 que limita las prestaciones sanitarias a las personas aseguradas ${ }^{18}$. Con ello queda excluido el colectivo inmigrante en situación irregular, salvo en los siguientes casos: urgencia por enfermedad grave o accidente; asistencia al embarazo, parto y posparto, y asistencia sanitaria a menores de dieciocho años ${ }^{19}$.

\section{LAS CONSECUENCIAS}

La puesta en práctica de las medidas expuestas viene dando como resultado numerosas consecuencias negativas. Así, los recortes en recursos humanos han ocasionado la ausencia de personal más formado y experimentado. Ello constituye un factor que redunda en detrimento de la calidad asistencial ${ }^{20}$, que, además, se está viendo afectada por los efectos de otros recortes que mencionamos anteriormente. Son numerosas las consecuencias que podrían considerarse en este sentido. Así, el aumento de las listas de espera. En la Comunidad Autónoma de Castilla-La Mancha, por ejemplo, alguna noticia ha llegado a estimar la cifra de lista de espera quirúrgica en más de 46.000 pacientes ${ }^{21}$. Por otra parte, según las estadísticas del Ministerio de Sanidad, Servicios Sociales e Igualdad, en junio de 2013 la lista de espera del Servicio Nacional de Salud era de 583.612 pacientes, siendo el tiempo medio de espera de 101 días $^{22}$. Igualmente preocupantes son las informaciones que hablan de «colapso» de hospitales o incluso de «hacinamiento» de pacientes. Dada la falta de camas y personal, en numerosas ocasiones no se ha recibido la atención adecuada en los hospi-

${ }_{18}$ Real Decreto-ley 16/2012..., op. cit., p. 31284.

19 Ibid., p. 31286. Como ya adelantamos, nos referimos a las circunstancias de este colectivo de manera más detenida en F. Centenera Sánchez-Seco, «Las acciones de las Defensorías del Pueblo...», op. cit.

${ }^{20}$ Sobre estas cuestiones vid. B. González López-Valcárcel y R. Meneu, «El gasto...», op. cit., p. 177, y J. CANTERO MARTínez, «Constitución y derecho...», op. cit., p. 4.

${ }^{21}$ E. G. Sevillano y M. R. Sahuquillo, «Ocho trayectos de 140 kilómetros para operarse de cataratas», El País, 6 de febrero de 2014, disponible en http://sociedad.elpais. com/sociedad/2014/02/06/actualidad/1391704682_852284.html (fecha de consulta: 11 de diciembre de 2015).

${ }^{22}$ Ministerio de Sanidad, Servicios Sociales e Igualdad, «Sistema de información sobre listas de espera en el Sistema Nacional de Salud. Situación a 30 de junio de 2013», p. 7, disponible en http://www.msssi.gob.es/estadEstudios/estadisticas/inforRecopilaciones/ docs/LISTAS_PUBLICACION_JUN13.pdf (fecha de consulta: 21 de enero de 2016). 
tales (aun cuando se cuenta con la buena disposición y voluntad del personal de trabajo), e incluso la espera para ingresar se ha llegado a contabilizar por días. Tales circunstancias han repercutido además negativamente en la intimidad de las personas, que han tenido que pasar por las situaciones descritas ${ }^{23}$.

El panorama anterior, junto con los aspectos a los que nos referiremos a continuación, y medidas como el copago están promocionando de algún modo la sanidad privada, aunque no sin dejar con ello numerosas razones para la reflexión: quienes tengan posibilidades económicas pueden evitar la situación que presenta la sanidad pública acudiendo a la privada; una práctica que además se presenta cada vez más sugerente si se tienen en cuenta las presiones para que las cantidades aportadas en este ámbito sean objeto de deducción fiscal ${ }^{24}$. En relación a la opción de la privatización, debe constatarse que su gestión también está dando lugar a consecuencias negativas. Así, a propósito del primer modelo que consideramos anteriormente, podemos decir que la derivación de pacientes a centros privados obliga a realizar largos trayectos a otras Comunidades Autónomas; trayectos que en numerosas ocasiones se presentan como la mejor opción si se compara con la de tener que soportar la lista de espera en el centro de salud al que se pertenece ${ }^{25}$. Por otro lado, son también muy preocupantes noticias como la que informa de que en el año 2013, 30.000 mujeres se quedaron temporalmente sin mamografías en Madrid a consecuencia de un retraso en la tramitación de un nuevo contrato con centros privados ${ }^{26}$.

${ }^{23}$ EFE, «La Federación por la Sanidad Pública denuncia el "colapso" en las urgencias hospitalarias», Público, 12 de enero de 2014, disponible en http://www.publico.es/ actualidad/federacion-sanidad-publica-denuncia-colapso.btml (fecha de consulta: 11 de diciembre de 2015); Redacción, «Denuncian el hacinamiento de pacientes en las urgencias de Tomelloso por falta de camas», Cadena Ser, disponible en http://www.radioazul.com/2014/02/20/ denuncian-el-hacinamiento-de-pacientes-en-las-urgencias-de-tomelloso-por-falta-de-camas/ (fecha de consulta: 11 de diciembre de 2015); M. CABRERA, «Pacientes hacinados en el pasillo esperan hasta tres días para ser ingresados en el Torrecárdenas», El Mundo, 20 de febrero de 2013, disponible en bttp://wwwelmundo.es/elmundo/2013/02/19/andalucia/1361303007. btml (fecha de consulta: 11 de diciembre de 2015), y Redacción, «Sindicatos denuncian el "colapso" de las urgencias del hospital de Cruces», Europa Press, 1 de abril de 2014, disponible en http://www.europapress.es/euskadi/noticia-sindicatos-denuncian-falta-camas-hospi tal-cruces-colapsa-urgencias-aumenta-carga-trabajo-20140401151913.html (fecha de consulta: 11 de diciembre de 2015).

24 P. Pérez Solís y Á. Díaz Álvarez, «El Real Decreto...», op. cit., pp. 39, 40 y 42.

${ }^{25}$ E. G. Sevillano y M. R. Sahuquillo, «Ocho trayectos...», op. cit.

26 E. G. Sevillano, «Madrid deja temporalmente a 30.000 mujeres sin mamografía preventiva», El País, 9 de octubre de 2013, disponible en bttp://ccaa.elpais.com/ccaa/2013/10/09/ madrid/1381310483_066233.html (fecha de consulta: 11 de diciembre de 2015). 
Debe decirse, además, aunque se trata de una cuestión de algún modo presente en el desarrollo expuesto, que determinadas medidas pueden estar afectando a la salud de las personas. No sin razón, se ha dicho que el hecho de evitar gastos en cuestión de salud en época de crisis puede tener importantes consecuencias, especificadas en un aumento de la mortalidad y morbilidad ${ }^{27}$. Desde numerosos ámbitos se ha manifestado que los recortes en sanidad están propiciando un importante riesgo para determinados colectivos vulnerables, entre los que encontramos a inmigrantes, pero también para personas que, por ejemplo, no pueden hacer frente al copago y que renuncian a los servicios sanitarios que necesitan porque no tienen suficientes posibilidades económicas ${ }^{28}$. Más concretamente, resulta muy preocupante comprobar que, a consecuencia de la medida en cuestión, hay pensionistas (entre el 12 y el 16 por 100 del colectivo) que no compran los medicamentos que necesitan por problemas de dinero. Igualmente, ofrece también motivos para la reflexión el hecho de que deba asumirse el coste por transporte ambulatorio no urgente. Son varios los colectivos que salen perjudicados con esta medida. Así, la población envejecida y con menos recursos de las áreas rurales o el colectivo que hace un uso habitual del servicio, donde encontramos a pacientes con tratamientos de hemodiálisis o tratamientos oncológicos ${ }^{29}$. Del mismo modo, debe tenerse presente el problema de que la población inmigrante en situación irregular queda fuera del sistema sanitario, salvo en los casos señalados anteriormente. En lo que respecta a esta cuestión, debe señalarse que las opciones que han tomado las Comunidades Autónomas son asimétricas: algunas amplían el acceso a personas no aseguradas y otras aplican el real decreto-ley estatal

${ }^{27}$ F. VAHID SHAHIDI et al., «Recortes profundos que hay que cortar por lo sano: crisis económica, políticas sociales y daños en la salud», Papeles de relaciones ecosociales y cambio global, núm. 113 (2011), pp. 107-119, esp. p. 110, disponible en bttp://www.fubem. es/medialecosocial/file/Cohesi\%C3\%B3n\%20Social/Desigualdad, \%20pobreza\%20y\%20 exclusi $\%$ C3\%B3n/recortes\%20profundos $\% 20 y \% 20$ da\%C3\%B1os $\% 20$ en $\% 20$ salud_F. $\% 20$ V.\%20SHAHIDI_C.\%20MUNTANER_V.\%20PUIG-BARRACHINA_J.\%20BENACH.pdf (fecha de consulta: 11 de diciembre de 2015). Debe tenerse en cuenta, no obstante, que esta fuente considera la crisis en diferentes ámbitos, además del español.

${ }^{28}$ Sobre la cuestión, por ejemplo, vid. MéDiCos DEL Mundo, Dos años de reforma sanitaria: más vidas en riesgo, 2014, pp. 6 y 7, disponible en http://www.medicosdelmundo.org/ index.php/mod.documentos/mem.descargar/FICHEro.documentos_Impacto-Reforma-Sanitaria -Medicos-del-Mundo_3ec0bdf9\%232E\%23pdf (fecha de consulta: 11 de diciembre de 2015), y F. Angora Mazuecos, «Público/privado...», op. cit., p. 221.

29 Sobre todas estas cuestiones vid. M. SÁNCHEZ BAYLE, «La contrarreforma...», op. cit., p. 64; J. Cantero Martínez, «Constitución y derecho...», op. cit., p. 5, y P. Pérez Solís y Á. Díaz Álvarez, «El Real Decreto...», op. cit., p. 43. 
sin ampliar el acceso ${ }^{30}$. En relación a todo lo dicho, resulta muy preocupante el dato de que, desde la aparición de la norma en cuestión, se han cuantificado más de 1.000 casos de vulneración del derecho a la salud ${ }^{31}$.

\section{EL PUNTO DE VISTA JURÍDICO}

\section{La perspectiva constitucional}

El derecho a la salud se reconoce en el capítulo III del título I de la Constitución, que lleva por título «De los principios rectores de la política social y económica». Más concretamente, el derecho que nos interesa aparece en el art. 43, cuyo texto es el siguiente:

«1. Se reconoce el derecho a la protección de la salud.

2. Compete a los poderes públicos organizar y tutelar la salud pública a través de medidas preventivas y de las prestaciones y servicios necesarios. La ley establecerá los derechos y deberes de todos al respecto.

3. Los poderes públicos fomentarán la educación sanitaria, la educación física y el deporte. Asimismo facilitarán la adecuada utilización del ocio».

En líneas generales, al considerarse la salud un derecho social, podemos afirmar que se inspira en los valores ${ }^{32}$ y principios que presiden la Constitución, que podemos especificar en la dignidad, la libertad y la igualdad $^{33}$. Aunque quizá en principio cabría establecer una relación más directa con la igualdad, no debe olvidarse que la distinción entre derechos de libertad (civiles y políticos) y derechos de igualdad (económicos, sociales y culturales) difícilmente puede seguirse si se tiene en cuenta que no es posible la libertad sin la satisfacción de unas condiciones mínimas ${ }^{34}$. Es

${ }^{30}$ Este esquema presentado a muy grandes rasgos tiene especificidades. Para un análisis de todo ello vid. Médicos del Mundo, Dos años..., op. cit., pp. 12 y 21.

${ }^{31}$ Ibid., p. 22.

32 G. Peces-Barba, R. Asís Roig y M. C. Barranco Avilés, Lecciones de Derechos Fundamentales, Madrid, Dykinson, 2004, p. 283.

33 G. Escobar Roca, «El derecho a la protección de la salud», en G. Escobar Roca (dir.), Derechos sociales y tutela antidiscriminatoria, Navarra, Aranzadi, 2012, pp. 1073-1178, esp. pp. 1099 y 1100, y M. LEÓN ALONSO, La protección constitucional de la salud, Madrid, La Ley, 2010, pp. 135-139.

34 J. MARTínez DE PIsÓN, «El derecho a la salud: un derecho social esencial», Derechos y Libertades, núm. 14 (2006), pp. 129-150, esp. pp. 133, 134, y M. LEÓN ALONSO, La protección..., op. cit., p. 136. 
decir, que si queremos una libertad real, hemos de tener satisfechas unas condiciones mínimas de salud. Conviene señalar, además, que desde hace ya tiempo, a la hora de fundamentar el derecho que nos interesa se incide en el argumento de las necesidades básicas, sin cuya satisfacción difícilmente podría llevarse una vida digna ${ }^{35}$ (entendemos como necesidades básicas no deseos ni preferencias, sino hechos objetivos, pues son circunstancias que no dependen de la intención de la persona) ${ }^{36}$.

Al tratarse de un derecho social, el derecho a la salud tiene carácter prestacional y supone, por tanto, una acción positiva, a diferencia de los derechos civiles y políticos, principalmente considerados de autonomía y participación, con base en una concepción negativa de la libertad, que supone la no interferencia en la actividad de las personas ${ }^{37}$. Más concretamente, podríamos decir que hemos de entender la protección de la salud no como la exigencia de la salud (algo que no es posible en muchas ocasiones), sino como la obligación de poner medios para dicha protección, si bien en ocasiones puede exigirse la obtención de un resultado (en el caso de enfermedades curables ${ }^{38}$.

Conviene señalar, no obstante, que los derechos sociales, y entre ellos el que nos ocupa, a diferencia de los derechos civiles y políticos, resultan con-

35 J. DE LuCAS y M. J. AÑón, «Necesidades, razones, derechos», Doxa, núm. 7 (1999), pp. 55-81, esp. p. 80; J. MARTíneZ DE PisÓN, «El derecho...», op. cit., pp. 134 y 135; M. LEÓN Alonso, La protección..., op. cit., p. 137, y G. Peces-Barba, R. Asís Roig y M. C. BarRanco Avilés, Lecciones de Derechos..., op. cit., p. 290.

36 J. DE LuCAS y M. J. AÑón, «Necesidades, razones...», op. cit., p. 61, y J. MartíneZ DE PISÓN, «El derecho...», op. cit., pp. 135 y 136.

37 J. Martínez de Pisón, «El derecho...», op. cit., p. 145, y G. Peces-Barba, R. Asís Roig y M. C. BarRanco Avilés, Lecciones de Derechos..., op. cit., p. 290. A propósito del derecho a la salud concebido como una de las posiciones individuales del derecho a la protección de la salud, se ha considerado el reconocimiento de una libertad negativa que legitima a la persona para exigir a los poderes públicos y a otras personas un comportamiento que no altere su salud. Vid. M. León Alonso, La protección..., op. cit., pp. 157 y 158. A esta circunstancia entendemos que se refiere también L. GONZÁLEZ Morán, «Introducción al derecho...», op. cit., p. 196. Ciertamente, es posible considerar esta dimensión en el derecho que nos ocupa, pero del mismo modo constatamos, como se hace en los trabajos señalados, que debe tenerse presente la dimensión positiva del derecho que nos interesa. El reconocimiento exclusivo de la vertiente negativa, al modo de restricciones negativas a lo Nozick (R. NozICK, Anarquía, Estado y Utopía, México DF, Fondo de Cultura Económica, 1974, pp. 40 y ss.), resulta insuficiente e inaceptable. Según esta última perspectiva, el derecho a la salud no incluiría el derecho a tener servicios de salud, sino el derecho a que la salud no sea dañada. Vid. M. Rollins et al., «Presentación de Anarquía, Estado y Utopía de Robert Nozick», Diánioa, núm. 34 (1988), pp. 271-293, esp. p. 279, disponible en bttp://dianoia.filosoficas.unam. $m x / f i l e s / 1213 / 6987 / 4671 / D I A 88 \_p r e s-N o z i c . p d f$ (fecha de consulta: 20 de enero de 2016).

38 G. Escobar Roca, «El derecho...», op. cit., p. 1091, y M. LeÓN Alonso, La protección..., op. cit., p. 154. 
trovertidos ${ }^{39}$. El hecho de que hayamos dejado constancia de la ubicación en la que se enmarca el derecho que nos interesa no es gratuito, dado que, según determinadas interpretaciones, no nos encontramos ante un derecho fundamental $-\mathrm{o}$ un derecho subjetivo públicocho social -o un principio rector subjetivado- que la ciudadanía puede exigir únicamente en la medida en que se establezca por ley; no siendo, por tanto, accionable de manera directa ${ }^{40}$. Esta es precisamente la interpretación que parece adoptarse en el Real Decreto-ley 16/2012, donde se constata reiteradamente que se está haciendo referencia a un principio rector ${ }^{41}$. Sin embargo, en ocasiones se ha cuestionado la postura que niega la existencia de auténticos derechos cuando hablamos de derechos sociales, una argumentación que encuentra apoyo en el carácter normativo de la Constitución ${ }^{42}$. Además, para los intereses que nos tocan no debe olvidarse que, según el art. 53.3 de la Constitución, dicha norma ha de informar «la legislación positiva, la práctica judicial y la actuación de los poderes públicos». En atención a ello, debemos entender, por tanto, que el marco constitucional supone un límite ineludible en aquellos ámbitos.

\section{La perspectiva internacional}

En el análisis que venimos presentando resulta también ineludible la consideración del ámbito internacional ${ }^{43}$. En este contexto, una de las

39 J. MARTínEZ DE PISÓN, «El derecho...», op. cit., p. 132.

40 Se refieren a estas circunstancias J. CANTERo MarTíneZ, «Constitución y derecho...», op. cit., p. 7; M. LEÓN Alonso, La protección..., op. cit., pp. 142, 143 y 144; L. GONZÁLEZ MorÁN, «Introducción al derecho...», op. cit., pp. 188 y ss.; J. MARTínEZ DE PISÓN, «El derecho...», op. cit., pp. 140, 141 y 142; G. Peces-Barba, R. Asís Roig y M. C. Barranco Avilés, Lecciones de Derechos..., op. cit., p. 283, y M. LEMA TomÉ, «La reforma sanitaria en España: especial referencia a la población inmigrante en situación administrativa irregular», Eunomía. Revista en Cultura de la Legalidad, núm. 5 (2013), pp. 95-115, esp. p. 99, disponible en bttp://eunomia.tirant.com/wp-content/uploads/2013/09/06-Eunomia5_Lema_final2.pdf (fecha de consulta: 11 de diciembre de 2015).

41 Real Decreto-ley 16/2012..., op. cit., p. 31284.

42 G. Escobar Roca, «Los derechos fundamentales sociales y la protección de la salud», Revista de Derecho Político, núm. 71-72 (2008), pp. 113-148, esp. p. 115, disponible en bttp://e-spacio.uned.es/fez/eserv.php?pid=bibliuned:DerechoPolitico2008-4EdsID=PDF (fecha de consulta: 11 de diciembre de 2015). Sobre esta postura defendida en otros trabajos y sobre otras que se enfrentan a ella vid. M. LEÓn Alonso, La protección..., op. cit., p. 147.

${ }^{43}$ Análisis más extensos desde esta perspectiva pueden verse en J. CANTERO MARTínEZ, «Constitución y derecho...», op. cit., pp. 15-20, y M. LEMA TOMÉ, «La reforma sanitaria...», op. cit., pp. 102-108. 
referencias más representativas a tener en cuenta es el Pacto Internacional de Derechos Económicos, Sociales y Culturales de 1966. En él se establece que: «Los Estados Partes en el presente pacto reconocen el derecho de toda persona al disfrute del más alto nivel posible de salud física y mental» ${ }^{44}$. Con ello, no obstante, debe tenerse también en cuenta lo que establece el art. 2 del pacto en cuestión ${ }^{45}$ :

«1. Cada uno de los Estados Partes en el presente Pacto se compromete a adoptar medidas, tanto por separado como mediante la asistencia y la cooperación internacionales, especialmente económicas y técnicas, hasta el máximo de los recursos de que disponga, para lograr progresivamente, por todos los medios apropiados, inclusive en particular la adopción de medidas legislativas, la plena efectividad de los derechos aquí reconocidos».

En atención al texto trascrito, parece que ha de entenderse que la efectividad del derecho a la salud y la obligación estatal contraída con el pacto podrían quedar limitadas en el caso de que no se contase con recursos para todo ello. En esta interpretación, sin embargo, no debe olvidarse que no es suficiente con una mera declaración que constate la insuficiencia de recursos, sino que es necesario justificar que se ha hecho todo lo posible para recabar posibles recursos. En esta línea argumenta el Comité de Derechos Económicos, Sociales y Culturales, que en el año 2000 adoptó la Observación General núm. 14 respecto del derecho al disfrute del más alto nivel posible de salud (art. 12). Merece la pena la trascripción del punto $47 \mathrm{de}$ su texto, enmarcado en el apartado de violaciones ${ }^{46}$ :

«Al determinar qué acciones u omisiones equivalen a una violación del derecho a la salud, es importante establecer una distinción entre la incapacidad de un Estado Parte de cumplir las obligaciones que ha contraído en virtud del art. 12 y la renuencia de dicho Estado a cumplir esas obligaciones [...] Un Estado que no esté dispuesto a utilizar el máximo de los recursos de que disponga para dar efectividad al derecho a la salud viola las obli-

44 Oficina del Alto Comisionado de las Naciones Unidas para los Derechos HumaNos, Pacto Internacional de Derechos Económicos, Sociales y Culturales, disponible en bttp:// www.ohchr.org/SP/ProfessionalInterest/Pages/CESCR.aspx (fecha de consulta: 11 de diciembre de 2015).

${ }^{45}$ Ibid.

46 «El derecho al disfrute del más alto nivel posible de salud. Observaciones generales aprobadas por el Comité de Derechos Económicos, Sociales y Culturales», Biblioteca de Derechos Humanos, Universidad de Minnesota, disponible en http://www1.umn.edu/ bumanrts/gencomm/epcomm14s.htm (fecha de consulta: 11 de diciembre de 2015). 
gaciones que ha contraído en virtud del art. 12. Si la limitación de recursos imposibilita el pleno cumplimiento por un Estado de las obligaciones que ha contraído en virtud del Pacto, dicho Estado tendrá que justificar, no obstante, que se ha hecho todo lo posible por utilizar todos los recursos de que dispone para satisfacer, como cuestión de prioridad, las obligaciones señaladas supra».

En las páginas siguientes nos referiremos a la solicitud de justificación requerida en el contexto que nos ocupa y también en otros, como veremos. Antes de ello, para concluir este apartado quisiéramos subrayar que, como ya se ha visto, en el pacto que consideramos se hace referencia al derecho que tiene «toda persona» al más alto nivel de salud; una expresión que también encuentra reflejo en el art. 22 de la Declaración Universal de Derechos Humanos, que establece que toda persona tiene derecho a obtener la satisfacción de los derechos sociales ineludibles para su dignidad y desarrollo de la personalidad ${ }^{47}$. Ciertamente, el hecho de hacer referencia a «toda persona» no se ajusta a la medida que deja fuera del derecho a la salud a la población inmigrante en situación irregular. En épocas de escasez, y cuando se dan procesos migratorios relevantes, se tiende a reforzar la distinción entre inmigrantes y nacionales, negando al primer colectivo determinados derechos sociales. Detrás de ello está la justificación de la razón de Estado, problemas de escasez, etc. Sin embargo, cabría preguntarse si estos argumentos son compatibles con aquel que ve en la dignidad humana la raíz de los derechos ${ }^{48}$. A propósito de esta cuestión conviene señalar además que, tras la publicación del Real Decreto-ley 16/2012, el Comité de Derechos Económicos, Sociales y Culturales recomendó que no se limitase el acceso de las personas a la salud, independientemente de la situación en la que se encuentren ${ }^{49}$.

47 Asamblea General de las Naciones Unidas, Declaración Universal de Derechos Humanos, disponible en https://www.un.org/es/documents/udhr/ (fecha de consulta: 11 de diciembre de 2015).

48 Sobre estas cuestiones vid. G. Peces-Barba, R. Asís Roig y M. C. Barranco Avilés, Lecciones de Derechos..., op. cit., pp. 212-215. Podría decirse, no obstante, que en el art. 22 se lee también: «habida cuenta de la organización y los recursos de cada Estado», algo que, de nuevo, podría inducir a pensar que la atención a la salud depende de aquellos aspectos. No obstante, aun con esta interpretación seguiría intacta la exigencia de racionalidad constatada anteriormente.

49 M. LemA Tomé, «La reforma sanitaria...», op. cit., p. 106. 


\section{Sobre la justificación de las medidas adoptadas}

Como ya hemos visto, el art. 43 de la Constitución no configura un modelo concreto en relación al derecho a la salud. Tal circunstancia, no obstante, se ha ido concretando a lo largo del tiempo con la actividad del legislativo ${ }^{50}$. Desde el punto de vista iusfilosófico, este proceso se justifica mediante el procedimiento de racionalidad discursiva ${ }^{51}$, en la línea de Habermas, que, a diferencia de la teoría de Rousseau sobre la soberanía popular, que no entra en el problema de la concreción de procedimientos en los que se ha de expresar la voluntad popular, se presenta en forma de acción comunicativa en los siguientes términos ${ }^{52}$. Los presupuestos comunicativos de la política deliberativa no alcanzan únicamente a la formación de la voluntad política en el Parlamento, sino también a los circuitos informales de comunicación política, que han de interactuar con el presupuesto anterior. Debe señalarse, además, que el modelo deliberativo se encuentra amenazado por numerosos factores, como son la burocracia y el influjo de los poderes sociales privados ${ }^{53}$. Desde este punto de vista, por tanto, la justificación viene dada por el consenso social sobre el tema que nos ocupa. Según algunas fuentes, dicho cauce fue el que se siguió en el caso español como respuesta a la necesidad de desarrollo constitucional $^{54}$, dando como resultado la Ley General de la Seguridad Social y la Ley General de la Sanidad ${ }^{55}$.

Teniendo en cuenta lo anterior, puede resultar interesante preguntarse en qué grado las medidas en materia sanitaria se ajustan al esquema descrito. A propósito de ello, resultan significativas las reflexiones en torno a aspectos ya señalados en este estudio, como, por ejemplo, la promoción de la privatización o bien los puntos de partida de las medidas que nos ocupan. Debe tenerse en cuenta que nos encontramos ante medidas proce-

${ }^{50}$ L. GonZÁLEZ MoRÁn, «Introducción al derecho...», op. cit., p. 192. Sobre la normativa desarrollada puede consultarse también G. EsCOBAR ROCA, «El derecho...», op. cit., pp. 1085-1090.

51 J. De LuCAS y M. J. AÑón, «Necesidades, razones...», op. cit., pp. 73 y 81.

52 J. C. Velasco Arroyo, La teoría discursiva del Derecho. Sistema jurídico y democracia en Habermas, Madrid, BOE-Centro de Estudios Políticos y Constitucionales, 2000, p. 175.

53 J. Habermas, Facticidad y validez. Sobre el Derecho y el Estado democrático de Derecho en términos de teoría del discurso, Madrid, Trotta, 1998, pp. 348 y 349.

54 J. Martínez de Pisón, «El derecho...», op. cit., pp. 139 y ss., y M. LeÓn Alonso, La protección..., op. cit., p. 150.

55 J. MARTínez DE PIsón, «El derecho...», op. cit., p. 142. 
dentes del seno de administraciones. Así, por ejemplo, desde el punto de vista estatal conviene recordar aquí el Real Decreto-ley 16/2012, que es una norma que emana del gobierno, aunque aprobada posteriormente en el Congreso - con los votos del partido que gobernaba en mayoría-, pero también objeto de múltiples críticas sociales ${ }^{56}$.

Más allá del planteamiento anterior, puede ser interesante que abundemos en el contexto jurídico con la intención de determinar si las medidas adoptadas se han ajustado o no a los presupuestos considerados anteriormente. El Estado democrático otorga libertad para aprobar la normativa que se estime pertinente en función del proyecto político que se pretenda llevar a cabo ${ }^{57}$. Ciertamente, tal actividad no puede estar mediatizada por regulaciones precedentes, producidas en una situación económica mejor ${ }^{58}$. Sin embargo, del hecho de que los derechos sociales conlleven efectos financieros no puede inferirse su no existencia. La competencia presupuestaria no constituye un principio absoluto ${ }^{59}$, entendido este como el que no puede ser desplazado nunca por otro principio ${ }^{60}$. Siendo esto así, y aun aceptándose que en la cuestión que nos ocupa nos encontramos ante un principio, el conflicto entre aquel y el de la competencia financiera debería resolverse mediante la ponderación ${ }^{61}$.

¿Tiene el argumento de las carencias económicas entidad suficiente para inclinar la balanza de la ponderación a favor de las medidas llevadas a cabo en sanidad? Al menos en lo que respecta a determinados aspectos, la pregunta ya se encuentra respondida de algún modo. Según señalan algunos estudios, el control del carácter deliberativo de las decisiones políticas ha de someterse a control judicial ${ }^{62}$, y lo cierto es que este control está encontrando reflejo en determinadas manifestaciones juris-

${ }^{56}$ M. LEMA Tomé, «La reforma sanitaria...», op. cit., pp. 97, 98 y 112.

57 J. Cantero Martínez, «Constitución y derecho...», op. cit., p. 6.

58 L. GonZÁlez Morán, «Introducción al derecho...», op. cit., p. 198.

59 R. AleXy, Teoría de los derechos fundamentales, Madrid, CEC, 2008, pp. 455 y 456.

${ }_{60}^{60}$ Ibid., p. 86.

${ }^{61}$ Se trata de la propuesta que, a propósito del principio de dignidad humana, se recoge en R. Alexy, Teoría de los derechos..., op. cit., p. 88. Más concretamente, se ha dicho que los derechos sociales pueden ser susceptibles de restricción siempre que aquella sea proporcionada, siendo un criterio para diagnosticar la desproporcionalidad el principio de prohibición de protección deficiente, que comprende los subprincipios de idoneidad, necesidad y proporcionalidad. Vid. M. LEÓN Alonso, La protección..., op. cit., pp. 541 y 542.

62 J. Habermas, Facticidad y validez..., op. cit., pp. 350 y 351. Sobre la cuestión vid. también C. R. SunsteIn, After the rights Revolution. Reconceiving the Regulatory State, Cambridge (Mass.), Harvard University Press, 1990, p. 164, a quien se refiere Habermas. Sobre la política deliberativa y el constitucionalismo americano, y los resultados de la ausencia de la primera, vid. además las pp. 102, 105 y 187 de la última obra. 
prudenciales. Así, por ejemplo, podemos referirnos a un Auto de 12 de diciembre de 2012 del Tribunal Constitucional. En él encontramos un pronunciamiento sobre la suspensión de la vigencia de numerosos artículos de una norma de la Comunidad Autónoma del País Vasco que regula el acceso a la salud para las personas que no tienen la condición de aseguradas en el Sistema Nacional de Salud ${ }^{63}$. En este caso se levanta la suspensión de la vigencia de los artículos relativos a la ampliación «del ámbito subjetivo del derecho a acceder a la asistencia sanitaria gratuita». La argumentación que conduce a esta conclusión es que el derecho a la salud y a la integridad física (en una interpretación que vincula los arts. 43 y 15 de la Constitución), así como el hecho de evitar riesgos para la salud de la sociedad, no pueden verse desvirtuados por el argumento de un ahorro eventual, que no se ha concretado ${ }^{64}$.

Interesante es también constatar que, frente a la decisión de restringir servicios sanitarios urgentes en determinados centros, el Tribunal Superior de Justicia de Castilla-La Mancha, mediante Auto de 29 de enero de 2013, suspendió la disposición administrativa ${ }^{65}$ que establecía la medida en cuestión en la Zona Básica de Tembleque (el Ayuntamiento de esta localidad interpuso el escrito de interposición donde se instaba medida cautelar provisionalísima para suspender la orden en cuestión) ${ }^{66}$. Entre los argumentos de esta decisión encontramos una justificación insuficiente a la hora de explicar por qué se debía cambiar la situación preexistente, además de la generación de inseguridad para la ciudadanía o los perjuicios que puede

${ }^{63}$ Decreto 114/2012, de 26 de junio, sobre régimen de las prestaciones sanitarias del Sistema Nacional de Salud en el ámbito de la Comunidad Autónoma de Euskadi, Boletín Oficial del País Vasco, núm. 127 (2012), disponible en bttp://www.lehendakaritza.ejgv.euskadi.eus/r48-bopv2/es/bopv2/datos/2012/06/1202973a.shtml (fecha de consulta: 26 de enero de 2016). El contenido recogido en el texto aparece en el art. 1 de la norma.

${ }^{64}$ Auto del Tribunal Constitucional 239/2012, de 12 de diciembre de 2012, Fundamento Jurídico $5 .^{\circ}$, disponible en bttp://www.tribunalconstitucional.es/es/jurisprudencia/ Paginas/Auto.aspx?cod=23581 (fecha de consulta: 11 de diciembre de 2015).

${ }^{65}$ Orden de 20 de noviembre de 2012, de la Consejería de Sanidad y Asuntos Sociales, sobre la atención sanitaria urgente y continuada en las zonas básicas de salud, Diario Oficial de Castilla-La Mancha, núm. 9 (2013), pp. 709-712, disponible en http://docm.jccm.es/portaldocm/descargarArchivo.do? ruta=2013/01/14/pdf/2013_145.pdfEtipo=rutaDocm (fecha de consulta: 11 de diciembre de 2015).

66 Auto de la Sala de lo Contencioso-Administrativo del Tribunal Superior de Justicia de Castilla-La Mancha de 29 de enero de 2013, antecedente de hecho $1 .^{\circ}$, y acuerdo de la Sala, Consejo General del Poder Judicial, disponible en http://www.poderjudicial.es/cgpj/ es/Poder_Judicial/Noticias_Judiciales/TSJ_Castilla_La_Mancha_Auto_definitivo_de_medi das_cautelares_solicitadas_por_el_Ayuntamiento_de_tembleque_en_las_urgencias_noctur nas (fecha de consulta: 11 de diciembre de 2015). 
ocasionar la disposición administrativa en términos de riesgo de mayores peligros para la salud ${ }^{67}$.

Podemos referirnos también al Auto de 27 de enero de 2014 del Tribunal Superior de Justicia de Madrid, que dejó en suspenso la externalización de varios hospitales iniciada por resolución administrativa. En aquel, además de constatarse las dimensiones extraordinarias de la gestión, que afectaba a cuestiones relativas a infraestructura, personal, contratos y toma de decisiones ${ }^{68}$, se estima que los cálculos llevados a cabo eran «meramente estimativos e hipotéticos» y que podrían no tener correspondencia con las circunstancias reales. En esta línea, se deja constancia también de los perjuicios que podría producir una futura anulación y lo difícil que sería la reversibilidad; algo que también repercutiría negativamente en la economía ${ }^{69}$.

Más recientemente, el Tribunal Constitucional se ha pronunciado sobre el art. 62 de la Ley 8/2012, de 28 de diciembre, de Medidas Fiscales y Administrativas de la Comunidad de Madrid ${ }^{70}$. Sobre dicho precepto se interpuso recurso de inconstitucionalidad, entendiendo que comportaría desigualdades entre la ciudadanía generadas en función de si se pertenecía a una zona de gestión directa o bien indirecta (en el caso de los hospitales que se citan en la norma) ${ }^{71}$. En la sentencia se considera que el precepto en cuestión únicamente contempla la posibilidad ${ }^{72}$ de llevar a cabo contratos y que no lesiona el art. 14 de la Constitución, pues aquel no establece desigualdad entre personas o grupos de personas ${ }^{73}$. Este pronunciamiento, no

${ }^{67}$ Auto de 29 de enero de 2013..., op. cit., Fundamento Jurídico 7. ${ }^{\circ}$

${ }^{68}$ Auto de la Sala de lo Contencioso del Tribunal Superior de Justicia de Madrid de 27 de enero de 2014, Fundamento de Derecho 4. ${ }^{\circ}$, Consejo General del Poder Judicial, disponible en bttp://www.poderjudicial.es/cgpj/es/Poder_Judicial/Tribunales_Superiores_de_Justicia/TSJ_Madrid/Noticias_Judiciales_TSJ_Madrid/El_TSJ_de_Madrid_mantiene_la_suspension_de_la_externalizacion_sanitaria (fecha de consulta: 25 de enero de 2016).

${ }^{69} \mathrm{Ibid}$., Fundamento de Derecho 7. ${ }^{\circ}$

${ }^{70}$ Ley 8/2012, de 28 de diciembre, de Medidas Fiscales y Administrativas, Boletín Oficial de la Comunidad de Madrid, núm. 310 (2012), p. 1031, disponible en bttps://www.bocm. es/boletin/CM_Orden_BOCM/2012/12/29/BOCM-20121229-2.PDF (fecha de consulta: 23 de enero de 2016).

${ }^{71}$ Sentencia del Tribunal Constitucional 84/2015, Fundamento Jurídico 7. ${ }^{\circ}$, Boletín Oficial del Estado, núm. 136 (2015), disponible en https://www.boe.es/boe/dias/2015/06/08/ $p d f s / B O E-A-2015-6386 . p d f$ (fecha de consulta: 23 de enero de 2016).

${ }^{72}$ Efectivamente, el primer punto del artículo en cuestión dice lo siguiente: «Se habilita al Servicio Madrileño de Salud para adjudicar contratos para la gestión del servicio público de asistencia sanitaria especializada». Vid. Ley 8/2012, de 28 de diciembre..., op. cit., p. 1031.

${ }^{73}$ Sentencia del Tribunal Constitucional 84/2015..., op. cit., Fundamento Jurídico $7 .^{\circ}$ 
obstante, se ciñe al test de constitucionalidad y no valora las posibles diferencias que pudieran tener lugar en la práctica ${ }^{74}$, ni tampoco se refiere a riesgos de carácter económico ${ }^{75}$.

\section{POR UN PROCESO DE RACIONALIDAD EX ANTE}

\section{Sobre la eficiencia}

En el contexto doctrinal español, durante mucho tiempo se ha venido obviando el análisis del proceso normativo, siendo la norma objeto de estudio a partir de su publicación. La labor de los tribunales, sin embargo, ha supuesto un reclamo mucho más fuerte como objeto de investigación. No obstante, desde hace unos años se está reivindicando la importancia de poner la mirada en el proceso de formación de políticas públicas ${ }^{76}$. Las circunstancias de crisis que atravesamos, así como las consecuencias negativas que hemos puesto de manifiesto, demuestran hasta qué punto puede ser interesante centrar la atención en el ámbito de estudio descrito y en su aplicación práctica. Las páginas siguientes se desarrollan en esta parcela. En ellas nos referiremos a algunas cuestiones que, a nuestro juicio, deberían haberse tenido en cuenta a la hora de proyectar posibles medidas. Comenzamos con este espacio, que dedicamos al tema de la eficiencia. Más adelante constataremos que resulta insuficiente una gestión de políticas públicas restringida a este ámbito. Sin embargo, ello no debe obstar para afirmar que su análisis es ineludible. A continuación nos referiremos a algunas cuestiones que, a nuestro juicio, convendría tener en cuenta en el contexto señalado.

Podemos, por ejemplo, fijarnos en la opción de la privatización y, a propósito de ella, preguntarnos hasta qué punto resulta preferible en términos de eficiencia. La cuestión no parece tener una respuesta definitiva. Según algunos estudios, no tenemos evaluaciones rigurosas (aunque sí evidencias

${ }^{74}$ Ello se gestionaría a través de los mecanismos de control y tutela que tiene el ordenamiento jurídico. Vid. Sentencia del Tribunal Constitucional 84/2015..., op. cit., Fundamento Jurídico 7 . $^{\circ}$

75 Frente a la constatación de dichos riesgos por la parte recurrente en relación a la «coherencia financiera del sistema», el Tribunal considera que la argumentación no puede abordarse desde el punto de vista constitucional. Vid. Sentencia del Tribunal Constitucional 84/2015..., op. cit., Fundamento Jurídico $8 .^{\circ}$

76 V. Zapatero, «De la jurisprudencia a la legislación», Doxa, núm. 15-16 (1994), pp. 769-790, esp. pp. 769 y ss. 
no concluyentes basadas en opiniones) acerca de si la privatización reporta más utilidad que otros modelos en los que no se contempla aquélla ${ }^{77}$. En otros casos se ha constatado que es erróneo afirmar que con la privatización se alcanzan niveles más óptimos ${ }^{78}$; que, lejos de resultar complaciente, el modelo está acentuando los problemas económicos ${ }^{79}$, o que tanto el modelo de iniciativa de financiación privada como el Modelo Alzira suponen sobrecostes bastante significativos ${ }^{80}$.

Otro aspecto interesante a tener en cuenta es el de los recortes, presentados como una medida de fácil implementación y que además supone ahorro ${ }^{81}$. Ciertamente, quizá en un primer acercamiento pudiera considerarse que, a corto plazo, medidas como las que conocemos pudieran suponer cierta contribución al ahorro. Sin embargo, a medio-largo plazo no son una solución ${ }^{82}$. Es más, resulta dudoso afirmar que, al menos en algunos casos, pueda hablarse de beneficios económicos incluso a corto plazo. Así, cabría preguntarse acerca del ahorro que supone la retirada de asistencia sanitaria, en los términos señalados, al colectivo inmigrante en situación irregular. Según el Ministerio de Sanidad, Asuntos Sociales e Igualdad, esta medida suponía unos 1.000 millones de ahorro. Sin embargo, en esta previsión parece que no se han tenido en cuenta los costes que podría ocasionar la medida adoptada. Así, por ejemplo, los derivados de la proliferación de enfermedades crónicas o infecciosas a consecuencia de la ausencia de tratamiento ${ }^{83}$. Con razón pensamos, como se ha dicho desde Médicos del Mundo, que no se ha demostrado el ahorro en relación a la medida en cuestión ${ }^{84}$.

Una reflexión parecida podría plantearse en torno al sistema de copago, sobre el que se ha dicho que ofrece un nivel de recaudación muy bajo ${ }^{85}$ y que ocasiona importantes costes. En este sentido, quizá sea significativo señalar que existen casos de trombosis de stent ocasionados a conse-

77 F. I. SÁnChez, J. M. Abellán y J. Oliva, «Gestión pública...», op. cit., p. 6, y P. Pérez Solís y Á. DíAz ÁlVAREZ, «El Real Decreto...», op. cit., pp. 41 y 44.

${ }^{78}$ F. Angora Mazuecos, «Público/privado...», op. cit., p. 220; R. RiezNiK, «La mercantilización...», op. cit., p. 54, y P. ACOSTA GALLO, «Restricciones de gasto...», op. cit., p. 77.

79 V. NAVARRO, «El error...», op. cit., p. 175.

${ }^{80}$ M. SÁNCHEZ BAYLE, «La contrarreforma...», op. cit., pp. 67 y 68.

${ }^{81}$ S. PeIRÓ, «Para salir...», op. cit., p. 1.

82 Ibid.

${ }^{83}$ M. LEMA Tomé, «La reforma sanitaria...», op. cit., p. 108.

${ }^{84}$ I. PARDO, «Sotoca: "Nadie ha demostrado el ahorro"», Cadena Ser, disponible en http://cadenaser.com/emisora/2015/07/16/radio_valencia/1437070884_027874.html (fecha de consulta: 30 de diciembre de 2015).

${ }^{85}$ P. Pérez Solís y Á. Díaz Álvarez, «El Real Decreto...», op. cit., p. 44. 
cuencia de no haber seguido el tratamiento por no tener dinero para asumir su coste. El gasto sanitario que ha de emplearse a consecuencia de la trombosis supera con creces al del tratamiento ${ }^{86}$. Quizá resulte interesante constatar también que el Consejo de Estado ha cuestionado la efectividad del copago en los servicios de traslados no urgentes ${ }^{87}$ o que numerosas Comunidades Autónomas han recurrido la Resolución de septiembre de 2013 argumentando, entre otras cosas, que la medida aporta escaso ahorro y supone costes, dado que habría que adaptar los sistemas informáticos y establecer un nuevo protocolo de trabajo ${ }^{88}$.

Ciertamente, cabría pensar que detrás de las medidas que nos ocupan había también previsiones de ahorro económico ${ }^{89}$. Sin embargo, frente a ello cabría oponer los datos que hemos venido exponiendo. Además, resulta también interesante reflexionar acerca de algunas decisiones posteriores en las que, en nuestra modesta opinión, aunque junto con otras justificaciones, de algún modo puede verse como telón de fondo la cuestión de la (falta de) eficiencia. Por una parte, en relación al colectivo inmigrante en situación irregular, quisiéramos considerar la noticia que informa del acceso de aquel a la atención primaria, y ello por razones de salud pública, de carácter práctico y para no evitar la saturación de urgencias ${ }^{90}$. Después de la constatación de estos factores resulta casi inevitable reflexionar acerca de una posible estimación de los costes que aquellos podrían conllevar. Por otra parte, unos meses antes de la anterior decisión se informaba de que no se aplicaría el copago ni a los transportes no urgentes en ambulancia, ni a las prestaciones ortoprotésicas y dietoterápicas. La medida en esta ocasión se respaldó apelando a los resultados que estaban dando los esfuerzos realizados por la ciudadanía. Sin embargo, no puede dejar de

\footnotetext{
${ }^{86}$ M. Diego, «Lágrimas de vergüenza», Salud a diario.es, 11 de abril de 2014, disponible en http://www.saludadiario.es/Opinion/2045/lagrimas-verguenza (fecha de consulta: 11 de diciembre de 2015).

${ }^{87}$ SeRvimedia, «El Consejo de Estado cuestiona el copago de ambulancias no urgentes», El Mundo, 10 de enero de 2014, disponible en http://www.elmundo.es/salud/2014/01/10/5 2cfdceeca474158218b4578. html (fecha de consulta: 11 de diciembre de 2015).

${ }^{88}$ Médicos del Mundo, Dos años..., op. cit., p. 17.

89 En cuanto a la normativa estatal, puede verse un resumen de algunos aspectos en E. De Benito, «El gobierno cifra en 7.267 millones el ahorro por el recorte en sanidad», El País, 26 de abril de 2012, disponible en http://sociedad.elpais.com/sociedad/2012/04/26/ actualidad/1335430943_769090.html (fecha de consulta: 30 de diciembre de 2015).

90 C. MARín, «Alonso enmienda a Mato: los inmigrantes irregulares volverán a tener atención sanitaria», El Mundo, 31 de marzo de 2015, disponible en bttp://www.elmundo. es/salud/2015/03/31/551a50f522601d677c864574.html (fecha de consulta: 30 de diciembre de 2015).
} 
señalarse que, aun cuando se constató que no influyó en la decisión tomada, algunos días antes de aquella el Consejo de Estado emitió el informe que cuestionaba la efectividad que podría suponer el copago en los transportes no urgentes ${ }^{91}$. Podríamos también fijarnos en el ámbito autonómico retomando, por ejemplo, el art. 62 de la Ley de Medidas Fiscales y Administrativas de la Comunidad de Madrid, que ha quedado derogado recientemente ${ }^{92}$. Poco tiempo antes, con ocasión de la aprobación del Proyecto de Ley de Medidas Fiscales y Administrativas (entendemos que se trata de la norma que ha llevado a cabo la derogación), junto con el anuncio de la homologación de varios hospitales al sistema de gestión directa apareció, entre otros, el argumento de más eficiencia y menos costes ${ }^{93}$.

En atención a todo lo dicho, y si se comparte el argumento que se viene desarrollando, cabría decir que el fin de lograr ahorro con las medidas señaladas no se ha conseguido o, al menos, no en la medida que probablemente se estimó en un principio. Con ello podría señalarse que en estos casos nos encontramos ante déficits relacionados con la racionalidad teleológica, dado que las medidas en cuestión no han dado lugar a los pretendidos fines que se habían previsto ${ }^{94}$.

\section{Más allá de la eficiencia}

En el apartado anterior hemos presentado algunas cuestiones que, a nuestro juicio, resultan ineludibles en un análisis desde el punto de vista de la eficiencia. Sin embargo, y como ya adelantamos, una gestión de políticas públicas dedicada exclusivamente a esta perspectiva es insuficiente. Ciertamente, no debe perderse de vista el objetivo de la eficiencia. Es más, incluso desde la perspectiva de la justicia la no optimización de recursos

${ }^{91}$ «Sanidad no aplicará el copago de ambulancias». El Mundo, 13 de enero de 2014, disponible en http://www.elmundo.es/salud/2014/01/13/52d42bc0e2704e8d578b4584.html (fecha de consulta: 30 de diciembre de 2015).

${ }_{92}$ Ley 9/2015, de 29 de diciembre, de Medidas Fiscales y Administrativas, Boletín Oficial de la Comunidad de Madrid, núm. 311 (2015), disposición derogatoria única, punto 2.l), disponible en bttps://www.bocm.es/boletin/CM_Orden_BOCM/2015/12/31/BOCM-20151231-1. $p d f$ (fecha de consulta: 22 de enero de 2016).

93 «Cifuentes integrará en el SERMAS las empresas públicas de seis hospitales externalizados», Europa Press, 12 de noviembre de 2015, disponible en http://www.europapress.es/madrid/noticia-cifuentes-integrara-sermas-empresas-publicas-seis-bospitales-externalizados-20151112100809. html (fecha de consulta: 21 de enero de 2016).

${ }^{94}$ Sobre este tipo de racionalidad vid. M. AtIEnZA, Contribución a una teoría de la legislación, Madrid, Civitas, 1997, pp. 37 y 38. 
escasos no es aceptable ${ }^{95}$. Es por ello por lo que la eficiencia debe tenerse en cuenta, como ya señalamos. Pero su análisis, aunque necesario, no debe ser exclusivo ${ }^{96}$. Con él han de considerarse además otros aspectos. En la checklist de las políticas públicas debe destacarse el ineludible análisis sobre la justicia, considerada en toda su extensión, dado que existen bienes que no se comercializan, pero que no pueden obviarse ${ }^{97}$. Como se ha dicho, sería conveniente un procedimiento que permitiese acuerdos razonables en un intercambio de razones que observase la consistencia con el sistema jurídico y los valores ${ }^{98}$. En la misma línea se ha apuntado que debe mantenerse la equidad, aunque sea con menos dinero 99 , o que la rentabilidad en términos económicos puede ir en perjuicio de la justicia, y que lo conveniente es armonizar las exigencias económicas con las éticas ${ }^{100}$. Por eso, junto con los análisis de eficiencia, conviene también incluir en la hoja de ruta aspectos como los que presentamos a continuación, que podrían enmarcarse dentro de la racionalidad ética ${ }^{101}$.

Una cuestión que debe tenerse en cuenta en el análisis que pretendemos desarrollar es aquella que hace referencia a las posibles repercusiones en la calidad de la asistencia sanitaria. Como ya vimos en este trabajo, los recortes han afectado a esta parcela, hasta el punto de repercutir negativamente en ámbitos como el de la intimidad. Lo cierto es que no parece que estas consecuencias fueran imprevisibles; un servicio no puede funcionar igual con una reducción importante de partidas presupuestarias ${ }^{102}$. Pero la previsión en cuanto al nivel de calidad en la asistencia no es el único aspecto que conviene tener en cuenta. En este análisis resulta además ineludible valorar las consecuencias de las medidas en la salud de las personas. En este sentido, resulta interesante constatar que los recortes en personal

${ }^{95}$ J. Conill SAncho, Horizontes de economía ética, Madrid, Tecnos, 2004, p. 252.

96 V. Zapatero, El arte de legislar, Cizur Menor, Thomson Aranzadi, 2009, p. 132, y N. GAROUPA, «Limites ideológicos e morais à avaliação económica da legislação», Legislação. Cadernos de Ciência de legislação, núm. 42/43 (2006), pp. 83-102, esp. p. 85.

${ }^{97}$ V. ZAPATERO, El arte..., op. cit., pp. 106 y 112.

${ }^{8}$ F. Lobo y M. A. RAmiro Avilés, «La justificación de las políticas de salud pública desde la ética y la eficiencia económica. Informe SESPAS 2010», Gaceta Sanitaria, núm. 24/Suppl. 1 (2010), pp. 120-127, esp. p. 122, disponible en bttp://e-archivo.uc3m.es/ handle/10016/14430\#preview (fecha de consulta: 11 de diciembre de 2015).

99 V. CAMPS, «El deber de sostener la equidad», Revista de Innovación Sanitaria y Atención Integrada, núm. 4/1 (2012), pp. 1-2, esp. p. 1, disponible en bttp://pub.bsalut.net/cgi/ viewcontent.cgi? article $=1053$ Econtext $=$ risai (fecha de consulta: 11 de diciembre de 2015).

100 J. Conill SANCho, Horizontes de economía..., op. cit., pp. 256 y 264.

101 Sobre este tipo de racionalidad vid. V. ZAPATERo, El arte..., op. cit., p. 20, y M. AtienZA, Contribución..., op. cit., pp. 39 y 40.

102 P. Acosta Gallo, «La nueva...», op. cit., p. 33. 
de enfermería dan como resultado un aumento de infecciones posoperatorias y de mortalidad ${ }^{103}$. Algo parecido cabría decir de las restricciones en los puntos de asistencia sanitaria urgente, medida que, aun cuando, según se señaló, tenía como fin la racionalización del sistema, ha generado mayores riesgos para la salud, concretados, por ejemplo, en el mayor tiempo de desplazamiento al centro asignado, que podría resultar crítico para salvar la vida ${ }^{104}$. La reflexión podría hacerse extensible también al copago que, como ya se ha confirmado repetidas veces con casos como los expuestos en este estudio, está resultando contraproducente para la salud. Quizá pudiera decirse que determinados colectivos especialmente vulnerables quedan exentos de aquel (así, por ejemplo, la población parada sin subsidio). Sin embargo, con ello debería haberse tenido en cuenta que la medida en cuestión podría resultar disuasoria para quienes, por dificultades económicas, tuvieran que enfrentarse a la disyuntiva de «o comemos, o tomo las pastillas»; una circunstancia que ha pasado ya de la mera hipótesis ${ }^{105}$.

Ciertamente, los colectivos más vulnerables son los que más están acusando los recortes llevados a cabo, y esta es una circunstancia que también debería haberse tenido en cuenta. A propósito de ella, resulta ineludible una reflexión en cuanto al problema de la desigualdad, ya existente antes de los recortes y agravado con su aparición ${ }^{106}$. La idea de que la eficiencia es compatible con cualquier desigualdad ${ }^{107}$ encuentra aquí varias manifestaciones. Como se ha visto, numerosos casos demuestran que las carencias económicas obligan a escoger entre el tratamiento o la atención de necesidades básicas como la alimentación. No podemos olvidar tampoco en este espacio al colectivo inmigrante en situación irregular. En este caso, la negación de la atención sanitaria en los términos expuestos, de por sí ya muy preocupante, ha venido dando como resultado la desatención de las víctimas de violencia de género irregulares o las víctimas de trata, que únicamente tienen asistencia sanitaria cuando se encuentran en periodo - de concesión no frecuente- de restablecimiento y reflexión ${ }^{108}$.

Por último, en el análisis que venimos planteando convendría haber hecho también previsiones de carácter cuantitativo, atendiendo para ello

${ }^{103}$ M. SÁNCHEZ BAYLE, «La contrarreforma...», op. cit., p. 67.

104 Así se constata en el Auto de 29 de enero de 2013..., op. cit., Fundamento Jurídico 8. ${ }^{\circ}$

${ }_{105}$ M. DiEGO, «Lágrimas de vergüenza», op. cit.

106 Tratamos la cuestión a propósito del ámbito laboral en F. CEnTEnera SÁnCHEZ-SECo, «Algunas reflexiones...», op. cit., p. 66.

${ }_{107}$ F. Lobo y M. A. RAmiro Avilés, «La justificación...», op. cit., p. 125.

108 M. Lema Tomé, «La reforma sanitaria...», op. cit., p. 110, y Médicos Del Mundo, Dos años..., op. cit., p. 18. 
a las circunstancias del contexto social en el que se iban a implementar las medidas. Es conocido el problema del paro que sufre España, con tasas que, por ejemplo, en 2013 alcanzaban el 25,9 por 100 o el 26,3 por 100 en $2012^{109}$. A propósito de estos datos, no debería olvidarse que el desempleo incrementa las posibilidades de tener enfermedades crónicas: depresión, trastornos de ansiedad o muertes prematuras ${ }^{110}$. Sin embargo, nos encontramos con que ante una previsión evidente de un periodo caracterizado por un aumento en los problemas de salud, se llevaron a cabo importantes supresiones en recursos humanos y materiales.

\section{Soluciones para las tensiones}

En el contexto de crisis que vivimos, la información vertida desde diferentes ámbitos ha venido suscitando la idea de que las medidas llevadas a cabo han sido ineludibles; siendo, por tanto, las tomadas en el ámbito de la sanidad un camino de obligado paso en el trayecto hacia la recuperación económica. No hay duda de que debía afrontarse una situación complicada. Sin embargo, y aun teniendo en cuenta aquello, ya de entrada cabría cuestionar la afirmación con la que hemos comenzado este apartado, al menos si se comparte el contenido desarrollado a la hora de referirnos al tema de la eficiencia.

No obstante, podría pensarse que, con todo, determinadas medidas han conseguido evitar costes a corto plazo, aun a consecuencia de dejar en el camino exclusiones y deficiencias que, según la argumentación expuesta, cabría entender que han sido inevitables. Sin embargo, frente a esta afirmación resulta interesante plantear la siguiente pregunta: ¿no podría haberse ahorrado la cantidad obtenida con las medidas adoptadas, o una incluso mayor, mediante una gestión diferente, preservando además con ella otros aspectos de justicia que ineludiblemente deben tenerse en cuenta? La respuesta negativa se antoja casi evidente si se tiene en cuenta la perspectiva unidireccional que consideramos anteriormente. Sin embargo, no son pocos los argumentos que contribuyen a fundamentar la respuesta contraria.

La cuestión planteada refleja la reivindicación que encontramos formulada en términos generales en numerosos estudios dedicados a la cien-

\footnotetext{
109 «Desempleo de España», Datosmacro.com, disponible en http://www.datosmacro. $\mathrm{com} /$ paro/espana? sector=ParoEsc=LAB- (fecha de consulta: 11 de diciembre de 2015).

${ }^{110}$ F. VAHID SHAHIDI et al., «Recortes profundos...», op. cit., pp. 107 y 108.
} 
cia de la legislación, relativa a la necesidad de tener en cuenta diferentes soluciones para decidirse por aquellas que sean más propicias ${ }^{111}$. De algún modo, esta recomendación encuentra una dimensión práctica en el ámbito que nos ocupa, en aquello que viene denominándose «desinversión». Con esta palabra se hace referencia a la práctica de no financiar aquellas acciones o procedimientos que no sean eficaces o a proponer alternativas más eficientes que las actuales. Una relación planteada en esta línea alcanza a aspectos tales como los chequeos de salud periódicos que no son eficientes ${ }^{112}$, las prescripciones inadecuadas, la coordinación deficiente en los casos de enfermedades crónicas ${ }^{113}$ o la burocratización en los trámites ${ }^{114}$. En este marco también podrían incluirse otras cuestiones que consideraremos en breve a propósito de las estimaciones económicas concretas. Debe decirse, no obstante, que algunas de las medidas llevadas a cabo podrían enmarcarse en esta línea. Estamos pensando, por ejemplo, en las que tienen como objetivo que no se acumulen medicamentos en los hogares o las relativas a la dispensación de medicamentos a un precio menor ${ }^{115}$. Sin embargo, como hemos visto y veremos a continuación, la relación puede ser mucho más nutrida.

Por otra parte, no debe olvidarse la correcta — no indiscriminadagestión de recursos materiales y humanos. Desde este punto de vista, una gestión conveniente es la que planifica adecuadamente el uso de quirófanos o camas y saca el máximo rendimiento posible a los centros. A propósito de esta circunstancia, quizá sea interesante señalar que, en muchas ocasiones, el personal médico del sistema público ejerce su profesión en el ámbito público y también en el privado. De este modo, por las tardes los hospitales no resultan eficientes ${ }^{116}$. Lo cierto es que esta última medida ha sido objeto de debate ${ }^{117}$, pero gestionada convenientemente puede resultar muy interesante para la consecución de los objetivos que nos ocupan.

Ciertamente, podría pensarse que las estimaciones económicas en relación a aspectos como los considerados no son significativas. Sin embargo,

111 A modo de ejemplo vid. V. Zapatero, El arte..., op. cit., pp. 100 y ss., y F. SÁinZ Moreno, «Antecedentes necesarios para pronunciarse sobre un proyecto de ley (art. 88 CE)», en F. Sáiz Moreno y J. C. Da Silva Ochoa (coords.), La calidad de las leyes, VitoriaGasteiz, Parlamento Vasco, 1989, pp. 15-50, esp. p. 41.

112 P. Pérez Solís y Á. Díaz Âlvarez, «El Real Decreto...», op. cit., pp. 44 y 45.

113 S. PEIRó, «Para salir...», op. cit., p. 2.

114 E. GónZález Hidalgo, «Un nuevo sistema...», op. cit., p. 80.

115 Real Decreto-ley 16/2012..., op. cit., p. 31290.

116 V. CAMPS, «El deber...», op. cit., pp. 1 y 2.

117 E. G. Sevillano y M. R. Sahuquillo, «Ocho trayectos...», op. cit. 
las previsiones que hacen algunos estudios demuestran hasta qué punto es cuestionable esta percepción. En este sentido son interesantes, por ejemplo, los cálculos desarrollados por la Federación de Asociaciones para la Defensa de la Sanidad Pública. En ellos se consideran medidas como la reducción del 50 por 100 de medicamentos innecesarios para personas menores de sesenta y cinco años, la prevención de ingresos hospitalarios por consumo de medicamentos, los controles de efectos adversos cuando se ingresa en el hospital, la mejora de la gestión de los ingresos evitando los innecesarios o el traspaso a la atención primaria de una cuarta parte de las consultas hospitalarias. Según las estimaciones realizadas desde este punto de vista, la recaudación ascendería a unos 9.553 millones de euros ${ }^{118}$. A ello debería añadirse, además, el ahorro que pudiera obtenerse con otras medidas a las que nos referimos anteriormente (por ejemplo, las relativas a la obtención de un mayor rendimiento de los centros), no estimadas en la previsión expuesta.

Análisis con cifras pueden encontrarse también en el Informe Cronos: hacia un cambio de paradigma en la atención a enfermos crónicos, donde se señala que el coste de cronicidad para el año 2020, calculado en unos 98.000 millones de euros, podría reducirse en unos 8.000-12.000 millones de euros si se llevasen a cabo gestiones adecuadas y consistentes. Así, por ejemplo, en el caso de la diabetes se propone el acceso al diagnóstico. En España hay muchos casos de diabetes sin detectar, y el diagnóstico precoz podría evitar que la afección avance a niveles más complejos. Se trata, además, de iniciativas sobre las que ya existen numerosas experiencias, de las que quisiéramos destacar, en el caso español, las desarrolladas en Cataluña y País Vasco, donde se participa en el De-plan ${ }^{119}$. Otra práctica interesante es la desarrollada con el Proyecto Prevenga en el Hospital Gregorio Marañón, que consiste en reducir las infecciones hospitalarias y que en un año ha proporcionado dos millones de euros aproximadamente. Algo parecido podría decirse en relación a determinadas propuestas sobre incorporación de personal. En este sentido, resulta interesante la noticia que informa de

118 «Casi 10 millones de euros ahorraría el gobierno con medidas de "eficacia" en el SNS, un 80 por 100 más que con el copago», Europa Press, 16 de abril de 2012, disponible en bttp://www.europapress.es/madrid/noticia-casi-10-millones-euros-aborraria -gobierno-medidas-eficacia-sns-80-mas-copago-20120416141058.btml (fecha de consulta: 2 de enero de 2016).

119 The Boston Consulting Group, Informe Cronos: hacia el cambio de paradigma en la atención a enfermos crónicos, 2014, disponible en http://www redaccionmedica.com/contenido/ images/INFORME_CRONOS_Embargado\%20miercoles\%209\%2023.59-1.pdf (fecha de consulta: 31 de diciembre de $201 \overline{5})$. 
que la incorporación de un/a profesional de enfermería supone un coste de 30.000 euros, pero también un ahorro superior a 200.000 euros, pues contribuirá a reducir las infecciones, los gastos en antibióticos, etcétera ${ }^{120}$.

Parece, por tanto, que existen antídotos para evitar - $\mathrm{O}$ al menos suavizar de forma considerable - las tensiones diagnosticadas, aunque, como hemos visto, no han recibido la atención deseable. Llegando a este punto podríamos preguntarnos por qué no tuvo lugar la prescripción. Son varios los trabajos que parecen ver en ello pretensiones neoliberales ${ }^{121}$. Si ha sido así, convendría recordar los problemas que ocasionan aquellas no solo en términos de eficiencia, sino también en el marco de la protección de los derechos ${ }^{122}$. Antes de esta crisis, otras han dado lugar al neoliberalismo a defender el argumento de que la única alternativa es desmantelar el Estado del bienestar, preparando así el camino a las privatizaciones y reducciones de las prestaciones sociales ${ }^{123}$. Podría, sin embargo, pensarse que las opciones en cuestión no se desarrollaron, no por la circunstancia anterior o por desatender los aspectos de eficiencia y justicia considerados - unos objetivos que se perciben como argumentación de las medidas adoptadas-, sino a consecuencia de un proceso deficiente desde el punto de vista de la racionalidad de las políticas públicas. Si la razón se encuentra en este punto, conviene recordar que, desde hace ya tiempo, en numerosos estudios se recomienda poner en marcha agencias de políticas públicas independientes ${ }^{124}$. Su presencia se aprecia en diferentes países, y también en España existen algunas de creación reciente ${ }^{125}$. En ellas tra-

120 Testimonio de Emilio Bouza, jefe del Servicio de Microbiología del Hospital Gregorio Marañón, en A. LóPEZ, «Cómo mejorar el sistema sanitario», El Mundo, 29 de enero de 2014, disponible en bttp://www.elmundo.es/salud/2014/01/29/52e8adfbca474198208b456a. btml (fecha de consulta: 10 de enero de 2016).

${ }^{121}$ F. VAHID SHahid et al., «Recortes profundos...», op. cit., pp. 114 y ss. (recordamos que esta referencia considera diferentes ámbitos); R. RIEZNIK, «La mercantilización...», op. cit., p. 52, y P. Acosta Gallo, «Restricciones de gasto...», op. cit., p. 75. P. Acosta GALLO, «La nueva regulación...», op. cit., p. 35, observa en los recortes propósitos ideológicos enfrentados al Estado de bienestar. Por su parte, V. NAVARRO, «El error...», op. cit., p. 174, considera que las causas del bajo gasto público en sanidad residen en la política conservadora; algo que también explica que en España el gasto sanitario privado suponga el 30 por 100 (el mayor de la Unión Europea) del gasto sanitario total.

122 Resulta interesante en este sentido el trabajo de N. KLEIN, La doctrina del shock. El auge del capitalismo del desastre, Barcelona, Paidós, 2007.

${ }_{123}$ M. LeÓN Alonso, La protección..., op. cit., p. 535.

124 V. Zapatero, El arte..., op. cit., pp. 93 y 112-115, y P. Acosta Gallo, «La nueva regulación...», op. cit., p. 34 .

125 J. Pinilla y A. García Altés, «La evaluación de políticas públicas. Informe SESPAS 2010», Gaceta Sanitaria, núm. 24/Suppl. 1 (2010), pp. 114-119, pp. 117 y 118, disponible en http://www.gacetasanitaria.org/index.php? $p=$ watermark $\mathcal{E}$ idAp $p=$ WGSEE EiiItem $=$ S021391 
baja personal experto externo y se presentan como el recurso idóneo para hacer posible la racionalidad en las políticas públicas, para evaluar aspectos como los que hemos ido considerando en las páginas precedentes, así como para afrontar las posibles influencias que pudieran ejercer los grupos de poder ${ }^{126}$.

\section{A MODO DE EPÍLOGO: LOS PROBLEMAS CONTINÚAN}

Uno de los objetivos de este estudio era considerar algunos aspectos ineludibles de lo que, a nuestro juicio, pudiera haber sido un análisis más apropiado ex ante, es decir, llevado a cabo durante el proceso de elaboración de las futuras medidas. Pensamos que un desarrollo como el descrito podría haber tenido lugar en dicho contexto, recurriendo al cauce deliberativo al que ya nos hemos referido y que, entre otras cosas, tiene como cometido poner encima de la mesa diferentes opciones para escoger las más apropiadas, tanto en función del criterio de la eficiencia, como de los que también han de considerarse en atención a la justicia. Pudiera pensarse que esta conclusión obvia que algunos de los resultados y soluciones que han aparecido en este estudio tienen una fecha posterior a la que marca la llegada de los recortes. En este sentido podría decirse que es fácil proponer ahora cuestiones que quizá no estaban tan claras en el momento en el que aparecieron las reformas. A nuestro modo de ver, no obstante, podría haberse avanzado en esa claridad recurriendo al cauce señalado.

En cualquier caso, lo cierto es que numerosos problemas siguen siendo recurrentes. Las últimas estadísticas sobre listas de espera quirúrgicas publicadas por el Ministerio de Sanidad, Servicios Sociales e Igualdad nos informan de que los datos han ido mejorando. Sin embargo, todavía son preocupantes. En diciembre de 2014 encontramos a 511.923 pacientes en lista de espera, y un tiempo medio de espera de ochenta y siete días ${ }^{127}$. La cuestión sigue formando parte de las noticias, junto con otras que se refie-

$111000169 X E$ Erigen $=$ gacetasanitaria $\varepsilon w e b=$ gacetasanitaria $\varepsilon$ url $A p p=h t t p: / / w w w . g a c e t a s a n i$ taria.orgE EstadoItem $=S 300$ EidiomaItem $=e$ (fecha de consulta: 11 de diciembre de 2015).

126 Sobre esta cuestión, a propósito de los recortes en sanidad, vid. P. Acosta Gallo, «La nueva regulación...», op. cit., p. 37. Sobre la recomendación del personal señalado vid. V. Zapatero, El arte..., op. cit., p. 111; J. Pinilla y A. García Altés, «La evaluación...», op. cit., p. 118, y U. KARPEN, «Institutional framework for an efficient Regulatory Impact Assessment», Legislação. Cadernos de Ciência de legislação, núm. 50 (2009), pp. 379-389, esp. p. 380.

127 Ministerio de Sanidad, Servicios Sociales e Igualdad, «Sistema de información sobre listas de espera en el Sistema Nacional de Salud. Situación a 31 de diciembre de 2014», 
ren a los copagos, los colapsos de urgencias, las rebajas en el número de camas o las reducciones de plantilla ${ }^{128}$ que, por cierto, en algún contexto están afectando negativamente al personal sanitario (empeñado en que no se viese dañada la calidad asistencial, ahora está acusando el esfuerzo) ${ }^{129}$. Podríamos referirnos también en este punto a la cuestión del paro que, como vimos, convendría tener en cuenta por las razones ya apuntadas. Aunque también en este caso se observa un descenso, la tasa del 21,4 por 100 en noviembre de 2015 todavía resulta muy considerable ${ }^{130}$. Además, debe señalarse que en nuestros días la calidad de los puestos de trabajo que se están creando no es la deseable en numerosos casos ${ }^{131}$.

Teniendo en cuenta las circunstancias expuestas, creemos que puede ser interesante volver la mirada a algunos modelos de dinámica legislativa donde encontramos conformadas, aunque no del mismo modo, diferentes pautas para encauzar el proceso ex ante. A propósito del mismo, se consideran cuestiones que de algún modo hemos adaptado al tema que nos ha venido ocupando: definición del problema, establecimiento de objetivos o consideración de posibles alternativas para poder acercarnos de la mejor manera posible a aquellos ${ }^{132}$. A este proceso, que podría enmarcarse dentro de la etapa legislativa, le sigue otro que tiene lugar en el momento poslegislativo, que se dedica a analizar el impacto de las normas en la sociedad teniendo en cuenta diferentes análisis de carácter teleológico o ético, entre otros ${ }^{133}$.

p. 7, disponible en http://www.msssi.gob.es/estadEstudios/estadisticas/inforRecopilaciones/ docs/LISTAS_PUBLICACION_DIC14.pdf (fecha de consulta: 21 de enero de 2016).

${ }^{128} \mathrm{~J}$. Mouzo Quintáns, «Protesta en Vall d'Hebron en favor de la sanidad pública», El País, 20 de enero de 2016, disponible en http://ccaa.elpais.com/ccaa/2016/01/20/ catalunya/1453292753_902731.html (fecha de consulta: 20 de enero de 2016); «El PSOE exige agilizar "las alarmantes" listas de espera», El País, 16 de enero de 2016, disponible en http://ccaa.elpais.com/ccaa/2016/01/16/madrid/1452970494_637006.html (fecha de consulta: 20 de enero de 2016), y S. Moreno, «Andalucía lidera los recortes en sanidad», El Mundo, 29 de septiembre de 2015, disponible en bttp://www.elmundo.es/andalucia/2015/ 09/29/560a7394ca474184238b456f.html (fecha de consulta: 20 de enero de 2016).

129 J. Mouzo QuinTás, «Los recortes por la crisis enferman a médicos y enfermeros», El País, 18 de enero de 2016, disponible en http://ccaa.elpais.com/ccaa/2016/01/17/ catalunya/1453052386_073049.html (fecha de consulta: 21 de enero de 2016).

130 «Desempleo de España», Datosmacro.com, disponible en http://www.datosmacro. com/paro/espana (fecha de consulta: 21 de enero de 2016).

${ }_{131}$ Nos hemos referido a ello en F. Centenera SÁncheZ-Seco, «Algunas reflexiones...», op. cit., pp. 64 y 65 .

132 V. Zapatero, El arte..., op. cit., pp. 84 y ss., y M. Atienza, Contribución..., op. cit., pp. 64 y ss.

133 M. Atienza, Contribución..., op. cit., pp. 65 y 69. En ocasiones se hace la distinción entre el proceso de evaluación anterior —Regulatory Impact Assessment (RIA)—y el proce- 
Este estudio pensamos que modestamente subraya algunas cuestiones que podrían ser de provecho para desarrollar un análisis ex post en la línea descrita, con todo lo que ello conlleva. Teniendo en cuenta el esquema que venimos considerando, se ha dicho que el mismo tiene carácter circular, es decir, el resultado obtenido en una fase posterior puede repercutir en una anterior ${ }^{134}$. Si la interpretación que hacemos de este planteamiento es correcta, entendemos que podría extrapolarse a lo desarrollado en este trabajo del siguiente modo: aquí se han diagnosticado déficits tanto en lo que respecta a la racionalidad teleológica como la ética, y se han considerado alternativas sugerentes que no parecen haber recibido la atención deseable. Tal análisis puede servir para reconsiderar las medidas llevadas a cabo, en relación a los aspectos señalados, y actuar en consecuencia recurriendo a otras opciones con vistas a mejorar la situación. Al menos en parte, pensamos que este ejercicio se ve reflejado en la percepción que localiza en la metódica de la legislación todos los aspectos que consideramos anteriormente (posibles alternativas de actuación, etc.), pero también dos fases más. Por una parte, la «evaluación retrospectiva de los efectos», es decir, el análisis de aspectos tales como la eficacia, efectividad y eficiencia, tomando además en consideración cuestiones como los efectos inesperados o secundarios. Por otra parte, la «adaptación de la legislación», es decir, el ejercicio de tratar de ajustar la legislación a los resultados que se han obtenido con la tarea anterior ${ }^{135}$.

Lo cierto es que en la época actual no faltan propuestas. Recientemente se han celebrado elecciones generales, y con ocasión de ellas las diferentes fuerzas políticas han reservado un espacio de sus programas para plantear alternativas en torno al tema que nos ha venido ocupando. Es interesante comprobar cómo en estos documentos se escriben palabras como «evaluación», «coordinación», «prevención», «desinversión»o «transparencia» ${ }^{136}$. El detalle resulta relevante, porque con ello parece que

so de evaluación posterior o seguimiento. Así, en N. GAROUPA, «Limites...», op. cit., pp. 84 y 85 (no obstante, la percepción no parece ser en todo caso la expuesta, en ocasiones se considera RIA ex ante, RIA concurrente y RIA ex post. Sobre ello vid. U. KARPEN, «Institutional framework...», op. cit., p. 380). Este planteamiento, aunque sugerente, resulta insuficiente, dado que parece comprender el ámbito económico. Como ya hemos visto, deben tenerse en cuenta otros factores. Sobre esta crítica vid. L. MADER, «Avaliação prospectiva e análise do impacto legislativo: tornam as leis melhores?», Legislação. Cadernos de Ciência de legislação, núm. 42/43 (2006), pp. 177-191, esp. p. 189.

134 M. ATIEnZA, Contribución..., op. cit., p. 70.

135 Sobre esta percepción de la metódica de la legislación vid. L. MADER, «Avaliação..»., op. cit., pp. 181-184.

136 Seguir avanzando, 2016-2020, PP, pp. 97-106, disponible en http://www.pp.es/sites/ default/files/documentos/programa2015.pdf (fecha de consulta: 10 de enero de 2016); El cam- 
se demuestra un acercamiento a aquellos parámetros que caracterizan una mejor política de regulación ${ }^{137}$. Sin embargo, ello no es suficiente, no al menos si queremos tomarnos en serio el proceso de elaboración de políticas públicas. Sirva señalar que, aun cuando se perciben aspectos como los citados y se proponen medidas para llevar a cabo mejoras, por lo general todo ello no se cuantifica en términos económicos ${ }^{138} \mathrm{o}$, cuando se hace, al menos por lo que llegamos a conocer, se echa en falta un análisis más pormenorizado en relación a aquellos conceptos en los que se pretende inci$\operatorname{dir}^{139}$. Así, por ejemplo, si se propone como medida terminar con el copago, convendría señalar qué cantidad en concreto se necesitaría para ello y cómo se obtendría dicha partida.

Pensamos que tratar de solucionar los problemas de la sociedad es empeñarse de la mejor forma posible en cuestiones como las recientemente expuestas, pero también en otras que pertenecen al ámbito axiológico y que, por cierto, aun cuando no producen ningún tipo de técnica legislativa ${ }^{140}$, no son ajenas a la elección de medidas. A la hora de evaluar las propuestas se ha de tener en cuenta su idoneidad, es decir, que causen los efectos que se esperan con ellas, pero también —una vez más— su legitimidad y proporcionalidad con respecto a los fines legislativos ${ }^{141}$.

bio que une, PSOE, pp. 197-209, disponible en http://www.psoe.es/media-content/2015/11/ PSOE_Programa_Electoral_2015.pdf (fecha de consulta: 10 de enero de 2016); Queremos, sabemos, podemos, Podemos, pp. 75-80, disponible en bttp://unpaiscontigo.es/wp-content/plugins/programa/data/programa-es.pdf (fecha de consulta: 10 de enero de 2016); El nuevo proyecto común para España, Ciudadanos, pp. 161-175, disponible en bttps://www. ciudadanos-cs.org/var/public/sections/page-programa-electoral-20d/programa-electoral.pdf? _v=164_0 (fecha de consulta: 10 de enero de 2016), y Programa participativo, UP, pp. 53-63, disponible en bttp://unidadpopular.es/wp-content/uploads/2015/12/Programa_participativo_ UP_2015.12.06.pdf (fecha de consulta: 10 de enero de 2016).

${ }^{137}$ C. M. Radaelli y F. De Francesco, Regulatory quality in Europe. Concepts, measures and policy processes, Manchester, Manchester University Press, 2007, p. 31. En esta obra se hace referencia a los siguientes aspectos: Regulatory Impact Assessment (RIA), consulta, simplificación, acceso y transparencia.

138 Sobre los análisis económicos en políticas públicas vid. V. ZaPATERo, El arte.., op. cit., pp. 131, 132, y C. M. RADAELli y F. De FrANCESCO, Regulatory quality in Europe..., op. cit., p. 31.

139 Según N. GaroupA, «Limites...», op. cit., p. 89, todos los costes y beneficios han de considerarse de manera explícita. Quizá pueda decirse que este tipo de apreciaciones se plantean a propósito del ámbito de las políticas públicas y que los programas electorales no requieren tanto detalle. Pensamos, sin embargo, que un acercamiento al mismo en la medida de lo posible, incluso en el contexto señalado, supone un compromiso mayor para con las circunstancias reales.

140 Sobre estas cuestiones vid. V. Zapatero, El arte..., op. cit., p. 132, y M. Atienza, Contribución..., op. cit., pp. 39 y 40, donde se hace referencia a la racionalidad ética.

${ }_{141}$ G. Marcilla CóRdoba, Racionalidad legislativa. Crisis de la ley y nueva ciencia de la legislación, Madrid, Centro de Estudios Políticos y Constitucionales, 2005, pp. 306 y 307. 